\title{
Paideusis
}

\section{A Dogma Not Worth Exhuming: Empiricism in Language, Intelligence, and Thought}

\section{Stephen P. Norris}

Volume 9, Number 1, 1995

URI: https://id.erudit.org/iderudit/1073248ar

DOI: https://doi.org/10.7202/1073248ar

See table of contents

Publisher(s)

Canadian Philosophy of Education Society

ISSN

0838-4517 (print)

1916-0348 (digital)

Explore this journal

Cite this article

Norris, S. (1995). A Dogma Not Worth Exhuming: Empiricism in Language,

Intelligence, and Thought. Paideusis, 9(1), 13-18.

https://doi.org/10.7202/1073248ar 


\section{A Dogma Not Worth Exhuming: Empiricism in Language, Intelligence, and Thought ${ }^{1}$}

\section{Stephen P. Norris, Memorial University of Newfoundland}

I will demonstrate that a central presupposition of Barrow's Language, Intelligence, and Thought (1993) is the empiricist dogma that there is "some fundamental cleavage between truths which are analytic, or grounded in meanings independently of matters of fact, and truths which are synthetic, or grounded in fact"' (Quine, 1953, p. 20). The analytic/synthetic distinction survived after Quine's revolutionary work only as a pragmatic tool for distinguishing language users' intentions in given contexts. However, in Barrow's recent book, the intrinsic, fundamental distinction as found in logical empiricism has been exhumed. Reliance on the dogma, I contend, threatens the positive aspects of many of Barrow's ideas. The role for philosophy of education in scholarly research on intelligence, which Barrow wishes to articulate, cannot be founded on an unsound philosophical theory. The empiricist dogma that the analytic and synthetic differ fundamentally is not worth exhuming.

I will give a very brief overview of the main points of Barrow's thesis, and mention several caveats about the overall agenda, though the latter will not be pursued in depth. Thence, I will turn to the main task of showing how the empiricist version of the analytic/synthetic distinction is presupposed in much of Barrow's argument. Finally, I will provide a brief sketch of how to study language, intelligence, and thought without the empiricist dogma.

\section{An Overview with Caveats}

I take Barrow's main points to be these four: (a) we should conceive of education as the development of understanding; (b) understanding comes in eight basic varieties, corresponding to eight developed traditions of enquiry-namely, those that deal with scientific, philosophical, mathematical, historical, aesthetic, moral, religious or metaphysical, and literary questions; (c) understanding corresponding to these eight traditions of enquiry is the only educationally interesting and relevant notion of being intelligent; and (d) developing intelligence, or understanding, in the sense defined above is equivalent to developing individuals' linguistic capacity.

I have three caveats that are significant enough to mention, but are not related closely to my central point. First, in my judgement, the most interesting thesis is the fourth-namely, that understanding in an educationally defensible sense should be equated with developed linguistic capacity in the eight traditions of inquiry. The idea is that learning science, for instance, involves far more than rote learning of facts, formulae, and definitions. It also involves grasping what we might call "the metalanguage of science"-notions of evidence, justification, observation, theory, causal generalization, hypothesis, and so on-and grasping the implications of this metalanguage for distinguishing between what we know with certainty, tentatively, or as conjecture. Curricula in science and other subjects sadly lack a focus on such a metalanguage. 
What is not acknowledged and employed in this volume, however, is any of the vast amount of work that has been done on this topic. To mention just one researcher in this area, David Olson (see, for example, Olson, 1994; Olson \& Astington, 1990; Olson \& Astington, 1993) has spent much of his career examining the development of such metalanguage from children's earliest years of speech. Such work has much to offer to Barrow's thesis, and is overlooked only at the expense of narrowing and undervaluing it.

Second, the idea of education as the development of understanding is put forward with no explicit recognition of the very large body of literature that argues for the narrowness of this view of education. The work of such philosophers of education as Nel Noddings (1984) and Jane Roland Martin (1985) on the role of care, compassion, and concern (in addition to understanding) on a conception of the educated person cannot simply be ignored. These alternative conceptions might be dismissed after argument, but this was not done with the result that Barrow's idea of education fails his own completeness criterion (p. 10).

Third, the idea that understanding is to be equated with understanding as found in eight basic traditions of enquiry cannot be taken as credible on the surface because it does not take account of the trenchant arguments that those very eight traditions are culturally and gender biased (see Harding, 1986). As in the previous case, this work is overlooked or ignored at one's peril. Three decades ago, one legitimately might not have had this concern, but this is not so today. It opens Barrow's work itself to the risk of being ignored because of a failure to meet his compatibility criterion (p. 10).

\section{An Empiricist Dogma}

At the heart of Language, Intelligence, and Thought is the view that understanding comes in eight basic varieties. This view is not so much a conclusion of the book as it is a presupposition of the very methodology that is employed to make the point. In particular, Barrow's distinction between philosophical and scientific questions betokens an enquiry based upon a sharp distinction in principle between conceptual and empirical issues that occupies much of the first half of the work. My contention is that the conceptual/ empirical distinction as used in this book is flawed and that its use leads to questionable claims.

Here is the distinction as Barrow makes it:

One of the most fundamental distinctions in our thinking is that between the empirical and the conceptual. Some claims that we make about the world are based upon, and need to be assessed by, the use of the senses, particularly observation. We explore such claims through experiment. Claims that fall into this category may range from abstruse hypotheses in the natural sciences to everyday commonsense claims such as that one's spouse is in the gardenshed. There is an enormous variety of techniques of experiment, a thousand different kinds of empirical inquiry that might be engaged in. Nonetheless, all claims of this type are radically different from conceptual claims, such as the question of whether intelligence is to be defined in terms of understanding, the main feature of which is that the evidence of the senses is ultimately irrelevant. To deal with the latter kind of question, one does not need to involve oneself in any kind of observation or experiment. (p. 60) 
In contrast to Barrow's claim that the conceptual and empirical are "radically different" from each other, Quine (1953) showed us that any claim of conceptual equivalence (for example, "A bachelor is an unmarried man") depends upon a claim of synonymy of meaning between a word and its definition; that any claim of synonymy of meaning depends upon claims about usage; that any claim about usage depends upon evidence from a lexicographer; and that the lexicographer "is an empirical scientist, whose business is the recording of antecedent facts" (Quine, 1953, 24). Thus, conceptual claims depend for their truth upon empirical claims, so there cannot be a radical difference between the two. Quine's view is that the distinction can be at most pragmatic, "turning upon our vaguely pragmatic inclination to adjust one strand of the fabric of science rather than another in accommodating some recalcitrant experience" (p. 46). Quine's version of pragmatism is perhaps less widely held today than his conclusion that there is no principled distinction between the conceptual and the empirical, which is a very widely adopted conclusion.

While engaging in what he describes as conceptual or philosophical analysis of "intelligence," Barrow demonstrates that Quine was correct because Barrow takes on the role of the lexicographer. Allow me to illustrate by referring to a number of passages. While considering a definition of intelligence that he eventually wishes to reject, Barrow says:

... we should simply be saying that to be intelligent means to be good at some subject, never mind what. But that is not what we mean by intelligence. It is not equivalent to specialist understanding of one sort or another. On the contrary, part of our conception of intelligence is that intelligent people can deal with all manner of problems, questions, or claims in an adequate way. (p. 61)

To say that something is "part of our conception of intelligence" and that something "is not what we mean by intelligence" are empirical claims requiring observational evidence for support. We would need to study what our (collective) conceptions are; we would need to study what we (collectively) mean. I expect differences would be found but, regardless of the outcome, it is certainly conceivable that differences would be found. Barrow's claims are distinctly testable using empirical methods.

In order that the preceding passage not be seen as isolated, let us examine a few more examples (all are chosen from two adjacent pages, though many similar examples exist throughout the text):

... intelligence is a concept that belongs in the rational camp. The notion of being intelligent and irrational strikes one as contradictory. (p. 66, italics added)

An intelligent reaction to a problem seems necessarily to imply a thought-out response. One would scarcely attribute intelligence to a person whose pronouncements and actions were not directed by good reason. (p. 66, italics added)

... there is another dimension to intelligence. While the most obvious and ubiquitous characteristic of people whom we regard as intelligent is that, when faced with a problem, they can cope with it rationally in the appropriate manner .... (p. 66, italics added) 
Sometimes what strikes us most immediately, and what most inclines us to judge people to be intelligent, is that they seem to see to the heart of a complex problem, to focus on what is really significant, and to ignore the irrelevant. (p. 67, italics added)

An intelligent person is not well conceived of purely in terms of rational deliberation and calculation. If only because the term represents such an accolade, we invest the intelligent person with some kind of spark. (p. 67, italics added)

A number of questions come to mind: Does the notion of being irrational and intelligent "strike one as contradictory"? Does one "scarcely attribute intelligence" to the persons so described? Do "we regard as intelligent" those actions named? Do the characteristics named "strike us most immediately," and is "what most inclines us" to judge people to be intelligent the characteristics named? Do we "invest the intelligent person" as described? These are all empirical questions; all are the job of the lexicographer to research; all are central to Barrow's analysis, which he claimed not to be empirical but conceptual.

\section{Philosophy of Education without Empiricist Dogmas}

Barrow's own words show us that the conceptual/empirical distinction that he wishes to hold falls prey to just the sort of problems Quine raised. Nevertheless, the distinction is used in the first half of the book to defend a thesis that there is a task for philosophers using conceptual analysis to study the concept of intelligence that is prior to the task of psychologists using empirical methods. Indeed, according to Barrow's thesis, psychologists cannot get their work off the ground until the philosophers have finished theirs. It seems to me that this view depends upon a profound misunderstanding of science, of empirical enquiry more generally, and of how human beings form referential intentions.

Allow me to illustrate the misunderstanding by referring to a few more passages from Barrow. Speaking of IQ tests, he says:

But how could one substantiate a claim about the relationship between performance on such tests and intelligence in the absence of some (other) satisfactory understanding of the latter notion? How could I know, to take an analogy, that a certain drug cured cancer (never mind how) if I didn't have a clear idea of what cancer was? (pp. 24-25)

Referring to some work of Arthur Jensen's on the correlation between IQ and reaction time, he says further:

... whether speed in thinking is an aspect of intelligence is a question that can only be answered by thinking about the concept, by reflection on what we mean, by argument about the kind of thinking that we presume to dignify with the title of "intelligent." (p. 28)

... without prior agreement on a reasonably full characterization of intelligence, nothing at all can be concluded about intelligence from this or any similar kind of empirical research. (p. 29) 
I am inclined to think that if we could acquire a "reasonably full claracterization of intelligence" that would satisfy Barrow's criteria, then there would be nothing left to conclude about intelligence. However, putting aside that issue, the very sorts of activities that Barrow claims cannot be done, are done. We have discovered that certain treatments cure cancer without having a clear idea of what cancer is. We can learn about the relationship between speed of reaction time and intelligence without having a clear idea of what intelligence is.

How is this done? The answer is long and involved, but a sketch is found in the following remarks by Harre:

The way in which theory serves as a guide for the rational exploration of the material world shows that neither of the slogans 'Sense determines refer. ence' and 'Reference determines sense' will do as a unique grounding for a theory of meaning. Sense determines the possibility of reference-that is, it directs a programme of research-while reference, when achieved, brings about the refinement of sense. (Harre, 33)

Barrow adopts the view that sense determines reference. The implication of Harre's remarks is that we form referential intentions using terms for referring to the natural world (such as "gold," "water," "cancer," and "intelligence") in a way different from how we form intentions using terms for referring to the world of artifacts (such as "hammer," "table," and "associate profes sor"). The meanings of words referring to artifacts can be determined largely in the manner Barrow describes by reflecting upon and studying linguistic practices. My earlier point was to indicate that even such reflection and study nevertheless involves empirical enquiry. The meanings of words referring to the natural world cannot be determined in this way, however. Reflection and study of our linguistic practices may help us to pick out the entities being discusst $d$. For example, our linguistic practices prior to modern science helped to determine the referent of the word "gold," but they were not useful for distinguishing gold from iron pyrites, or for informing us that gold is that element with atomic number 79. These latter meanings are traceable to scientific enquiry into the nature of the entities picked out by prescientific locutions. No amount of reflection upon linguistic practices without further empirical enquiry would have led to them. In addition, having atomic number 79-a property found through scientific enquiry-is more central to the meaning of "gold" than its being yellow, a property derived from reflection upon prescientific linguistic practice.

Intelligence, it seems to me, is more like "gold" and "water" than it is like "hammer" or "table." When introduced into the language first, the word "intelligence" presupposed a vague explanatory hypothesis about the causes of certain events. At a minimum, its usage presupposed that something about the material constitution of certain living entities causes (or enables) them to act in various ways. To get beyond this, scientific investigation and not just reflection on language is needed. To be sure, clear conceptualization will also be needed. But this conceptualization cannot all be done before the scientific investigation begins, and it cannot be divorced from the scientific investigation. Reiterating Quine, conceptual and empirical investigation must be carried out together, and the judgements of whether what we are now facing is an empirical issue and now a conceptual issue are judgements that can be made only in context. 
I conclude that we shall not find an adequate educational theory of the development of understanding that makes a decontextualized distinction in principle between types of questions and types of understanding, such as between the philosophical and scientific. Barrow's notions of language development and its role in education are important and potentially fruitful. However, for proper articulation, they need the backdrop of sound empirical scientific enquiry and of philosophy shorn of empiricist dogmas.

\section{Notes}

Thi; is a slightly revised version of a paper that was delivered at the Annual Meeting of the Canadian Society for the Study of Education, Calgary, June 1994.

\section{References}

Barrow, R. (1993). Language, Intelligence, and Thought. Aldershot, Hants: Edward Elgar.

Harding, S. (1986). The Science Question in Feminism. Ithaca, NY: Comell University Press.

Harré, R. (1986). Varieties of Realism. Oxford: Basil Blackwell.

Martin, J.R. (1985). Reclaiming a Conversation. New. Haven, CT: Yale University Press.

Noddings, N. (1984). Caring: A Feminine Approach to Ethics and Moral Education. Berkeley, CA: University of California Press.

Olson, D.R. (1994). The World on Paper. Cambridge: Cambridge University Press.

Olson, D.R., \& Astington, J.W. (1990). "Talking about text: How literacy contributes to thought." Journal of Pragmatics, 14, 705-721.

Olson, D.R. \& Astington, J.W. (1993). "Thinking about thinking: Learning how to take statements and hold beliefs." Educational Psychologist, 28, 7-23.

Quine, W.V.O. (1953). From a Logical Point of View. Cambridge, MA: Harvard University Press. 